\title{
A CASE OF COMPLETE BRANCHIAL FISTULA
}

\author{
Major K. B. HUGHES, M.B., F.R.C.S., D.L.O., R.A.M.C. \\ The Queen Alexandra Military Hospital, Millbank
}

SUMMARY: A case of complete branchial fistula in a 25 year old airman is described. The embryology, clinical aspects of this case and literature are reviewed.

\section{Case history}

A 25 year old Royal Air Force (R.A.F.) airman was referred in May 1973 complaining of intermittent episodes of discomfort, swelling and a discharging pustule at the base of the left side of his neck.

The swelling had been noticed on and off all his life and it was only the recent episode of discomfort and change in character of the discharge which caused him to seek medical advice. Previously the discharge had been serous, but on recent occasions had become purulent and blood-stained. Associated with this change he had on several occasions experienced vague discomfort in his throat and had coughed up small amounts of blood-stained material, which he thought was coming from his throat.

Examination revealed a small pustule over the sternal head of the left sternomastoid muscle. On palpation above it, a thickened cord-like structure was found extending up towards the angle of the jaw. Compression downwards brought an egress of pus. No abnormality was detected in the mouth, pharynx or on the other side.

A diagnosis of branchial fistula was made and confirmed radiologically. The small opening in the neck was cannulated with a drawn-out glass pipette and injected with radio-opaque material. A complete fistulous tract was demonstrated with spilling out of contrast medium into the pharynx in the region of the left tonsil (Figs 1 and 2).
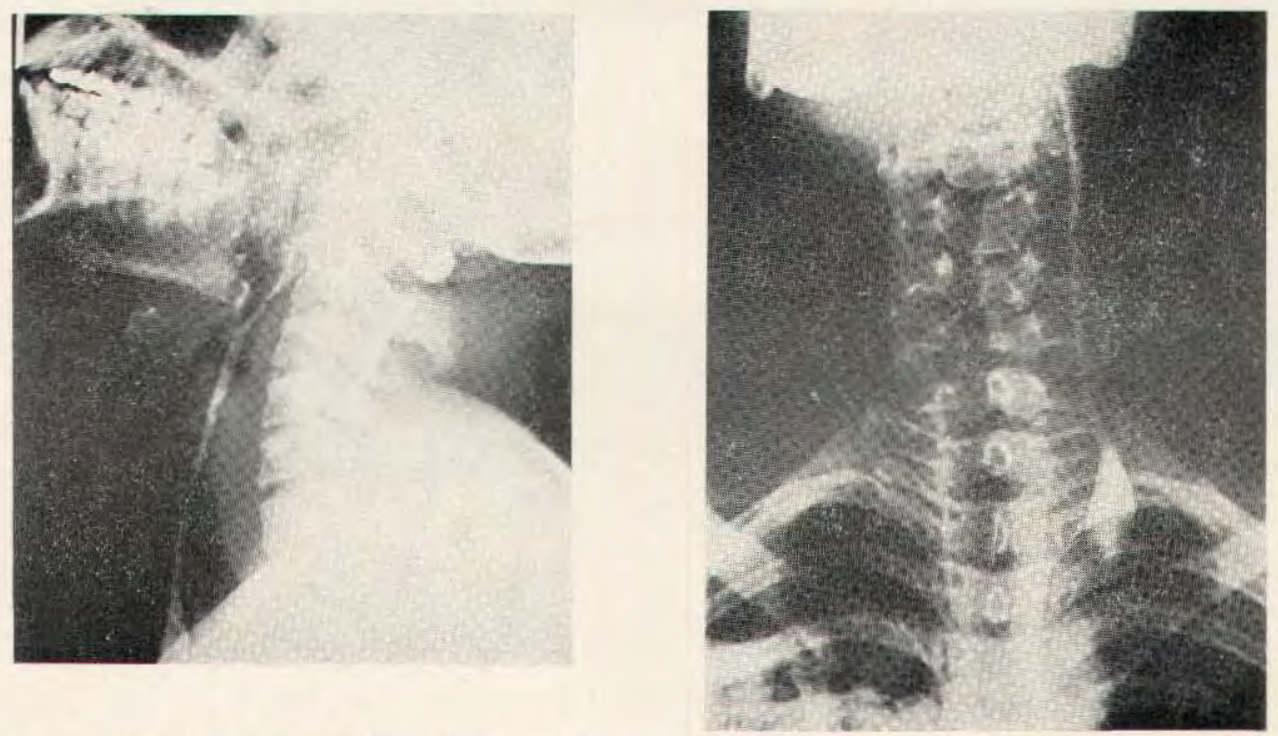

Figs. 1 and 2. A complete fistulous tract is demonstrated with spilling out of contrast medium into the pharynx in the region of the left tonsil. 
This opening was not visualised on direct oral examination or under anaesthesia during the subsequent operation.

The patient's family history demonstrates well the hereditary aspects of these cases (Fig. 3). Aird (1957) has stated that 25 per cent of cases have a family history. Binns and

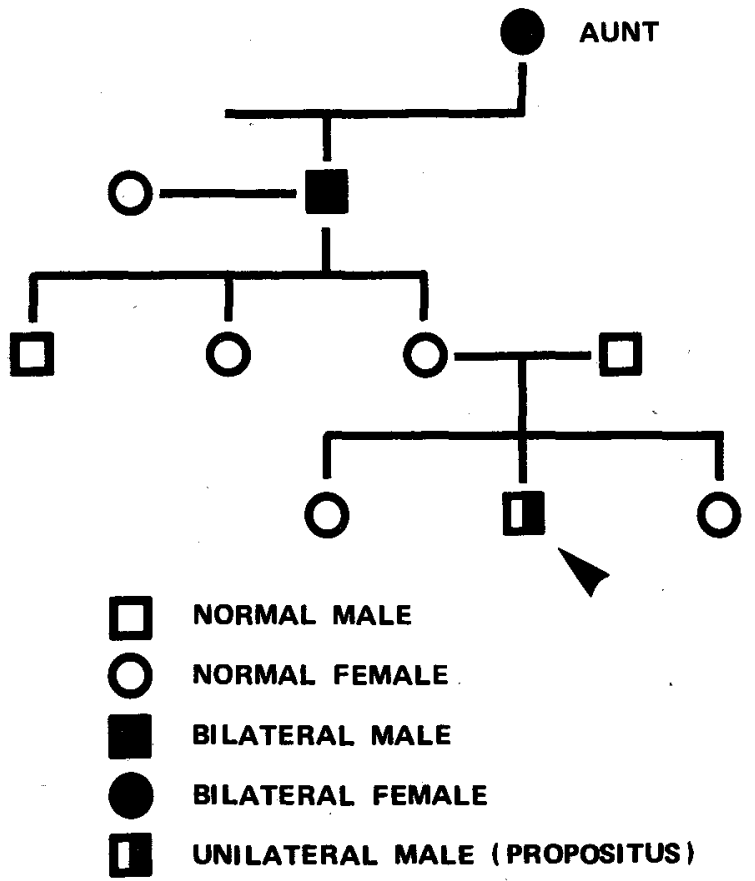

Fig. 3. Family History. (Produced by courtesy of The Department of Medical Illustration, Manchester Royal Infirmary, Manchester 13.

Lord (1965) reported five cases of bilateral branchial fistulae in three generations of a family.

In 148 cases reported by Gross (1953) 25 were bilateral (17 per cent); Wilson (1955) in his Hunterial Lecture stated that fistulae were bilateral in at least 30 per cent of cases.

\section{Embryology}

The branchial arches appear in the somite stage of development of the ambryo (20 to 30 th day) and are well seen by the 10 somite stage (about 23 rd day). These arches and their associated pouches are involved in the development of the face, jaw, ear, hyoid apparatus and associated structures.

The intervening pouches break down in lower vertebrates to establish gill clefts; this situation never normally occurs in man. The musculature of each arch is supplied by a special visceral efferent nerve and the related endoderm by branchial afferents from the nerve of the arch concerned (post-trematic) and by a branch from the succeeding arch (pre-trematic). Each arch has associated with it a branchial or aortic arch artery.

While the superficial aspects of the mandibular and hyoid arches are undergoing the changes resulting in the formation of the pinna, the more caudal arches remain small and come to lie in the depths of the retrohyoid depression-the cervical sinus. Growth changes, principally a backward extension of the hyoid arch, lead to the over-lapping. 
of this sinus and create the conditions which can lead to abnormalities in this region (Fig. 4).

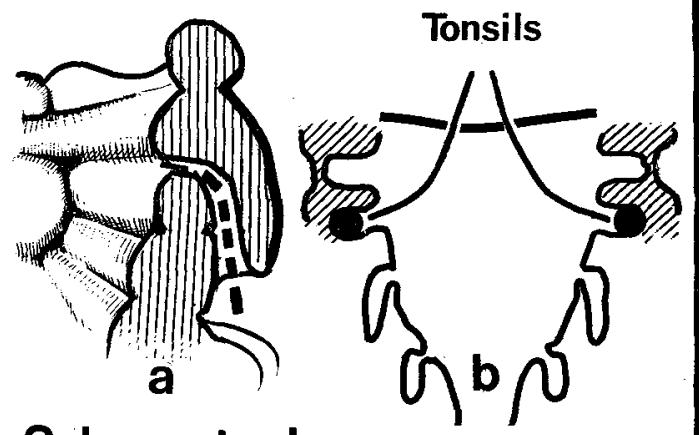

Scheme toshow Cervical sinuses(a) \& a cyst (b)

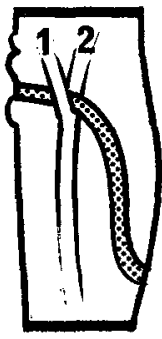

a

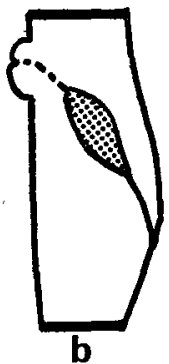

NOTE

Upper illustrations are

horizontal sections

Lower illustrations are

vertical sections

Fig. 4.

The adult structures developed from each arch have been carefully worked out. The second and third arches contribute the following structures (Table 1).

The origin of the common type of branchial fistula is the subject of argument. The various arguments, namely that it derives from an abnormally persisting second branchial cleft as opposed to the theory of Wenglowski (1913) that it is a persistence of the thymic duct, are dealt with at length by Wilson (1955). His view based on his own findings and the work of Frazer (1926) is that the complete branchial fistula is a persistent second branchial cleft.

The main points of evidence in support of this are that it passes between the internal and external carotid, cranial to the glossopharyngeal and hypoglossal nerves (Fig. 5), gains an investment from the platysma and stylopharyngeus (second and third arch respectively) and opens up on the posterior pillar of the fauces.

\section{Operation}

The patient was recommended and accepted the operation of excision of the fistulous tract. 
Table I

Structures of the second and third arches

\begin{tabular}{l|l|l}
\hline \multicolumn{1}{c|}{ Site } & \multicolumn{1}{|c}{ ARCH TWO } & \multicolumn{1}{c}{ ARCH THREE } \\
\hline SKELETON & $\begin{array}{l}\text { Stapes } \\
\text { Stylohyoid ligament } \\
\text { Small cornul of hyoid } \\
\text { Upper part of body of hyoid }\end{array}$ & $\begin{array}{l}\text { Greater cornu of hyoid } \\
\text { Lower part of body of hyoid }\end{array}$ \\
\cline { 2 - 2 } & Stapedial & Parts of common and internal carotids \\
\hline NERVE & Facial & Glossopharyngeal \\
\hline MUSCLES & $\begin{array}{l}\text { Diagastric (posterior belly) } \\
\text { Facial } \\
\text { Stapedius } \\
\text { Stylohyoid }\end{array}$ & Stylopharyngeus \\
\hline
\end{tabular}

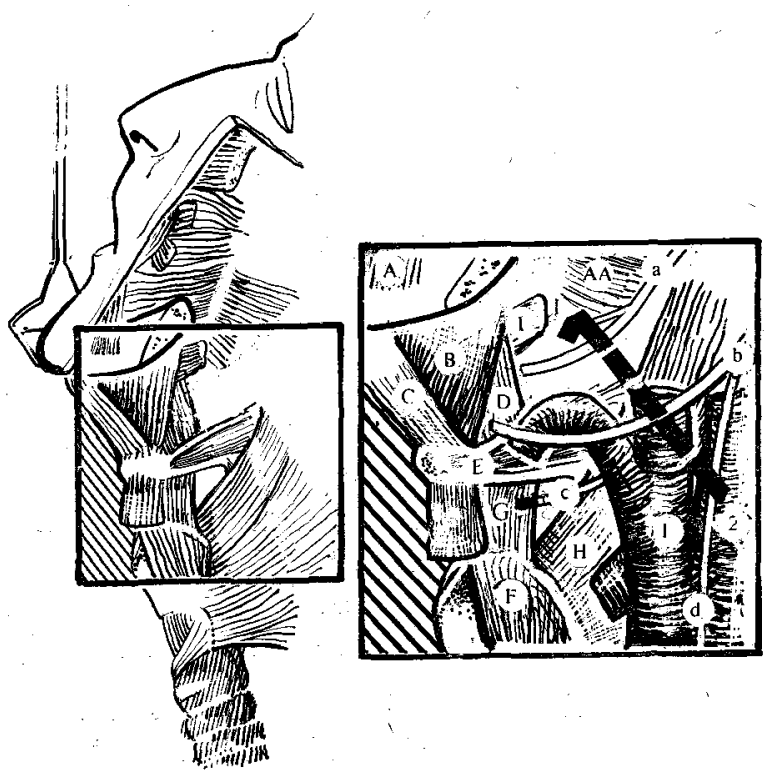

Legend. a. Glossopharyngeal nerve. b. Hypoglossal nerve. c. Internal laryngeal nerve. d. Vagus nerve. AA. Depressor anguli oris muscle. A. Superior pharyngeal muscle: B. Mylohyoid muscle. C. Diagastic muscle. D. Hypoglossus muscle. E. Middle constrictor muscle. F. Sterno-hyoid muscle. G. Thyrohyoid muscle. $\mathrm{H}$. Inferior constrictor muscle. I. Styloglossus muscle.

(left External carotid artery, with lingual and superior thyroid branches. (right Internal carotid artery.

Fig. 5.

The choice of incision is between a vertical one along the anterior border of the sternomastoid, or two horizontal "step ladder" incisions. The access through the former is excellent, but cosmetically and surgically it is a bad incision. Access through a two step ladder incision is good.

A lower horizontal neck incision was used encompassing the fistula opening. A tube-like structure was dissected out and followed upwards through the platysma. It ascended superficial to the main vessels from which it was easily separated. By retracting 
the top edge of the wound it could be safely followed to the level of the middle of the thyroid cartilage. A further horizontal incision at the level of the hyoid was made extending through the platysma and identifying the tract of the fistula. The bridge of the skin between the two incisions was raised and the fistulous tract passed up and delivered through the upper wound. The tract was followed up now lying on the internal jugular vein and passing superficial to the hypoglossal nerve. It then turned medially deep to the external carotid vessels, but superficial to the internal carotid. By retracting the fistula anteriorly at this point it was kept clear of stylopharyngeus and the glossopharyngeal nerve as it passes to the pharynx. With an assistant applying pressure from within the pharynx, the fistula was divided flush with the pharyngeal wall. Both wounds were closed in layers without drainage. The patient made an uneventful recovery.

At the point where the fistula turns inwards close to the glossopharyngeal nerve, Gross (1953) makes the point that the accessory nerve should be identified in this area. This particular tract was so easy to dissect that this was not done, but in a case where inflammation had led to more fibrosis it would be a necessary precaution.

\section{Pathology}

In many cases the fistula is of nearly uniform calibre throughout its length and is lined by a mixture of stratified mucosal and ciliated columnar epithelium.

The specimen removed at operation was $11 \mathrm{~cm}$ long $x 1.5 \mathrm{~cm}$ at its widest point. The track was filled with mucoid debris and lined by pseudostratified and ciliated columnar epithelium. There was abundant lymphoid tissue in the wall of the tract which contained debris and inflammatory cells.

There is good reason to remove this anomaly as most become infected sooner or later. Aird (1957) recommends they be removed between 6 and 8 years of age or as soon after that age as the patient presents. Buckingham and Lynn (1974) reporting on 35 children with cysts, sinuses and fistulae report a high incidence of infection (45 to 50 per cent) at an early age and recommend surgical excision at a much earlier age. However, they do not separate fistulae and sinuses and so the figures are unhelpful.

One consideration in excising this particular fistula was that the change in character of the discharge might mean a malignant change had supervened. Whereas carcinomatous change is now accepted in branchial cysts (Willis 1958)_-" branchiogenic carcinoma ", albeit rarely, no case of malignancy has been reported in a branchial fistula.

\section{Acknowledgement}

My thanks are due to Squadron-Leader J. Williams, R.A.F. who produced the $\mathrm{X}$-rays for me.

\section{REFERENCES}

AIRD, I. (1957). Companion in Surgical Studies. E. \& S. Livingstone Ltd., Edinburgh and London. P.432.

Bins, P. M. and LoRd, O. C. (1965). J. Laryng. 79, 172.

Buckingham, J. M. and LynN, H. B. (1974). Mayo Clin. Proc. 49, 172.

Frazer, J. E. (1926). J. Anat. (Lond.) 61, 132. 
Gross, R. E. (1953). The Surgery of Infancy and Childhood. W. B. Saunders \& Co., Philadelphia and London. P. 949.

Wenglowski, R. (1913). Klin. Chir. 100, 789.

Willis, R. A. (1958). The Borderland of Embryology and Pathology. Butterworth \& Co., Ltd., London. P.279.

Wilson, C. P. (1955). Ann. roy. Coll. Surg. Engl. 17, 1

\section{Preliminary Announcements-Corps Occasions for 1977}

Provisional dates are as follows:-

R.A.M.C. Annual General Meetings of General and Officers Funds,

R.A.M.C. Association and Corps Mess Fund

W.O's \& Sgts. (Past \& Present) Annual Dinner at the Princess Hall, Civic Centre, Aldershot

Army Medical Services Swimming Gala

10 June

R.A.M.C. Officers' Dinner (7-15 for 8 p.m.)

7 July

R.A.M.C. Officers' ' At Home' (4-6 p.m.)

Army Medical Services Sports Meeting

Army Medical Services Drumhead Service at the R.A.M.C. Training Centre and R.A.M.C., R.A.D.C. \& Q.A.R.A.N.C. Associations Annual Lunch

R.A.M.C. Golfing Society-Spring Meeting-Worplesden Golf Club 